\title{
Tool machinery vibrations frames comparison concerning welded or moulded manufacturing structures
}

\author{
Dan Ovidiu Glavan ${ }^{1, *}$, and Theoharis Babanatsas ${ }^{1}$ \\ ${ }^{1}$ University “Aurel Vlaicu” of Arad, Faculty of Engineering, 310130 Arad, Romania
}

\begin{abstract}
Precision of manufactured object is the main goal for all engineers in modern times. The times of massive structures with low displacement have passed. We are looking forward now to develop new type of structures with controlled deformations easy to predict and therefore to correct in order to obtain the ,ideal" product. The paper is analysing tool machinery frames vibrations in welded and moulded manufacturing structures ,the vibrations being studied in both horizontal and vertical planes and the loads are simulated as manufacturing loading pulses generated by special excitation electromagnetic devices, in order to determine advantages and disadvantages of using them for frames in projecting, producing and exploitation of tool machinery.
\end{abstract}

\section{Theoretical considerations}

In welded and moulded structures in any machinery bed frame structure appears vibration in the moment of work.

This vibration are unmaintained free dynamic balance equation (1), vibrate movement is of the form:

$$
m \ddot{x}+c \dot{z}+k x=0
$$

where: $m$ - mass; $c$ - damping coefficient; $k$ - spring constant; $x$ - acceleration; $\ddot{x}$ displacement; $\dot{Z}$-speed [1-3].

King $m$ and noting (2):

$$
\frac{c}{m}=\lambda \text { and } \frac{k}{m}=p^{2}
$$

we get (3):

$$
\ddot{x}+\lambda \dot{z}+p^{2} x=0
$$

where $p$ - pulsation of the system (4):

\footnotetext{
* Corresponding author: glavan@,fortuna.com.ro
} 


$$
p=2 \pi f_{m} \frac{2 \sqrt{c}}{T}
$$

where: $f$ - frequency oscillation; $T$ - period oscillation.

Now results the differential equation which solving this equation yields with solutions that provide information about the movement of the structure, from characteristic points [3, 7-8].

We calculate the amplification baseline vibration (5):

$$
x_{1}=x_{0} e^{-\lambda_{t}}
$$

The vibration amplitude until the touch (6) result:

$$
x_{2}=x_{0} e^{-\lambda_{T}}
$$

The intensity of depreciation results (7) are:

$$
\frac{x_{1}}{x_{2}}=e^{\lambda_{T}}
$$

The logarithmic decrement damping (8) is:

$$
\delta=\frac{\ln x_{1}}{x_{2}}=\lambda_{T}
$$

And with this we can calculate the logarithmic decrement damping factor $\lambda(9)$ :

$$
\lambda=\frac{\delta}{T}
$$

\section{Experimental conditions}

Bed frame structures can be manufactured with welded frame or with casted frame under the same conditions of settlement in the foundation. That means that a rubber hammer can be applied in order to generate a signal pulse on the bed frame structure, in the headstock and in the movable doll [6].

This pulses applied in both directions (vertically and horizontally). This impulse give a feedback value from frameworks in the form of a value that can be interpreted and recorded. For each point and place where was applicated this impulse taking both values of impulse (vertically and horizontally). In this way was registered the values that was obtained from vibration amplitude, oscillation period and amortization period.

With these parameters, we obtained the intensity depreciation $\delta, \lambda$ and the pulsation damping response $\mathrm{p}$. Means vibrometer measuring and transducer [1-5].

To the framework poured appear higher frequency response (own bed frame and no settlement construction) which do not appear welded to the framework. Comparing the damping factors $\lambda$ there is better the frame welded [9-11].

The values of vibration to tailstock are in table 1 . 
Table 1. Vibration to tailstock.

\begin{tabular}{|l|l|l|l|l|l|l|l|l|}
\hline \multirow{2}{*}{ Parameters } & $\begin{array}{l}\text { Vertical impulse } \\
\text { Vertical reaction } \\
\text { (Figure 1) }\end{array}$ & $\begin{array}{l}\text { Horizontal } \\
\text { impulse } \\
\text { Vertical reaction } \\
\text { (Figure 2) }\end{array}$ & $\begin{array}{l}\text { Vertical impulse } \\
\text { Horizontal } \\
\text { reaction } \\
\text { (Figure 3) }\end{array}$ & $\begin{array}{l}\text { Horizontal } \\
\text { impulse } \\
\text { Horizontal } \\
\text { reaction } \\
\text { (Figure 4) }\end{array}$ \\
\cline { 2 - 10 } & B.S. & B.T. & B.S. & B.T. & B.S. & B.T. & B.S. & B.T. \\
\hline $\mathrm{T}_{1}(\mathrm{~ms})$ & 150 & 175 & 35 & 120 & 35 & 110 & 56 & 80 \\
\hline $\mathrm{T}_{2}(\mathrm{~ms})$ & 25 & 50 & 18 & 50 & 25 & 50 & 18 & 50 \\
\hline $\mathrm{f}_{1}(\mathrm{~Hz})$ & 7 & 6 & 29 & 8 & 29 & 9 & 20 & 12 \\
\hline $\mathrm{f}_{2}(\mathrm{~Hz})$ & 40 & 20 & 56 & 40 & 40 & 20 & 56 & 20 \\
\hline $\mathrm{p}_{1}(\mathrm{rad} / \mathrm{s})$ & 44 & 38 & 182 & 50 & 182 & 57 & 126 & 75 \\
\hline $\mathrm{p}_{2}(\mathrm{rad} / \mathrm{s})$ & 251 & 126 & 352 & 251 & 251 & 126 & 352 & 126 \\
\hline$\overline{\mathrm{x}}_{1}$ & 2 & 2,2 & 1,0 & 1,2 & 1,1 & 1,2 & 1,4 & 1,2 \\
\hline $\mathrm{x}_{\mathrm{i}}+1$ & 1,6 & 1,5 & 0,7 & 0,9 & 0,5 & 1,0 & 1,2 & 0,5 \\
\hline$\delta$ & 0,2 & 0,3 & 0,4 & 0,3 & 0,8 & 0,3 & 1,5 & 0,9 \\
\hline$\lambda^{*} 10^{-3}$ & 1,4 & 1,7 & 11,4 & 2,5 & 22,8 & 2,8 & 26,7 & 11,2 \\
\hline
\end{tabular}

The graphic value of vibration to tailstock are in figures 1, 2, 3 and 4 .

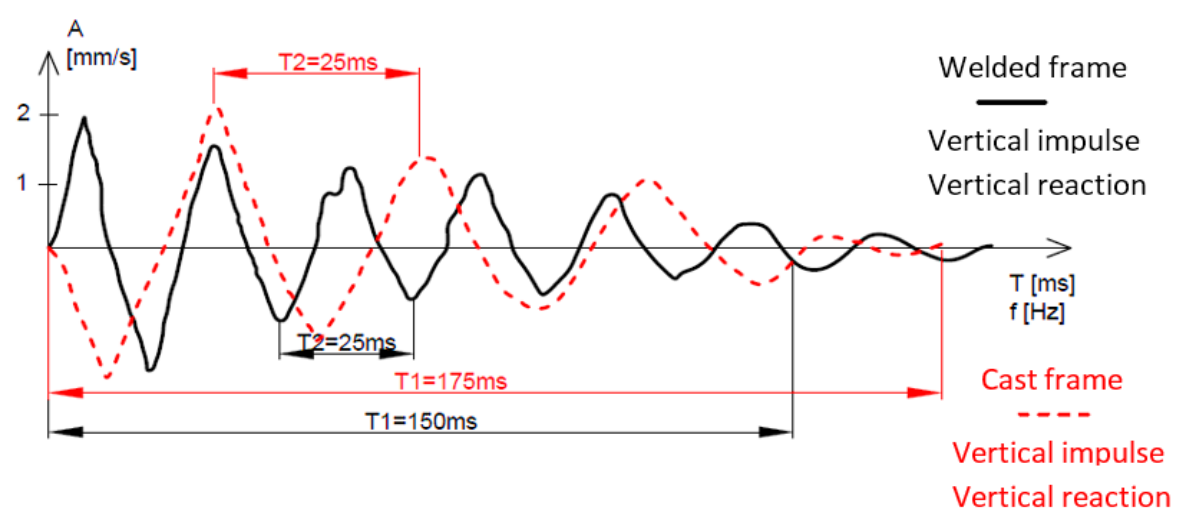

Fig. 1. Vertical impulse and vertical reaction.

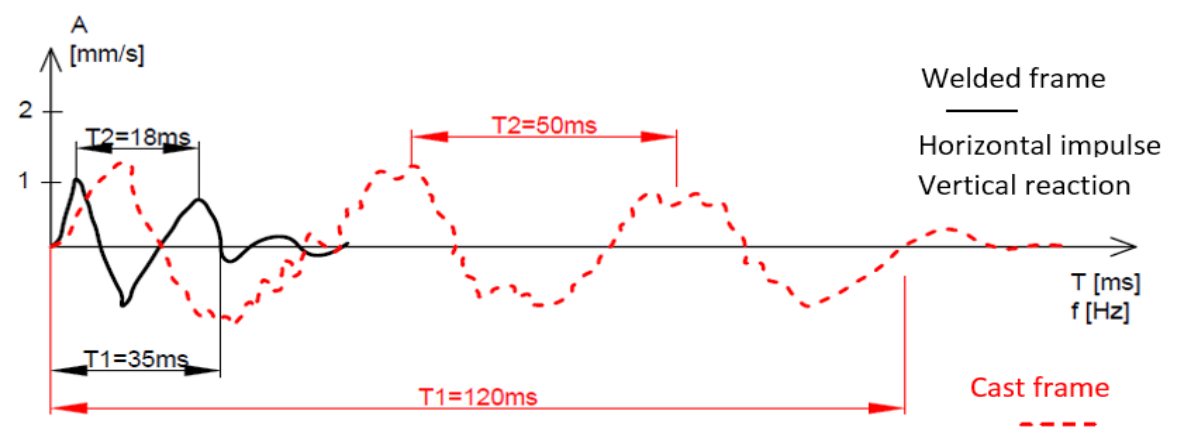

Horizontal impulse

Vertical reaction

Fig. 2. Horizontal impulse and vertical reaction. 


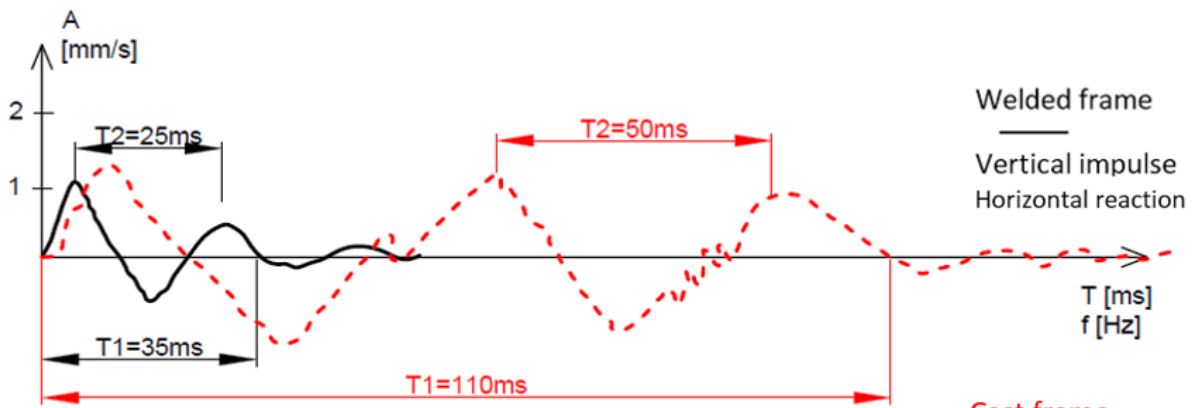

Cast frame

Vertical impulse

Horizontal reaction

Fig. 3. Vertical impulse and horizontal reaction.

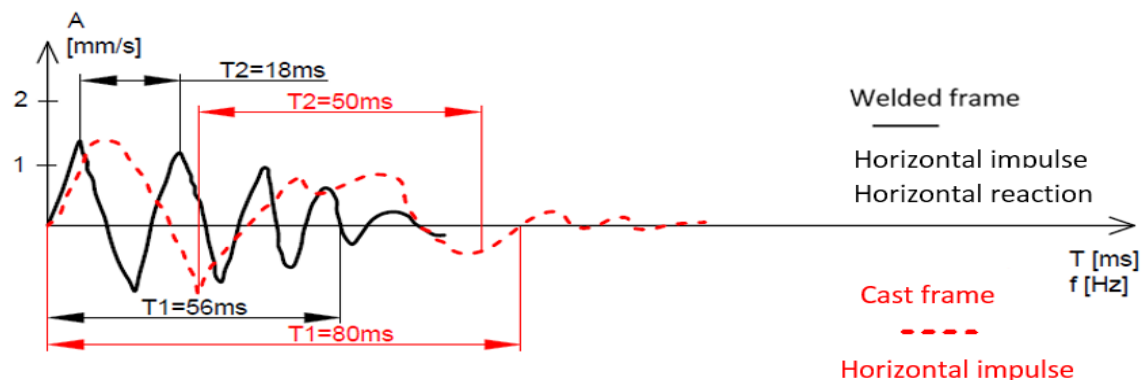

Horizontal impulse Horizontal reaction

Fig. 4. Horizontal impulse and horizontal reaction.

The value of vibration to headstock are in table 2 .

Table 2. Vibration to headstock

\begin{tabular}{|l|l|l|l|l|l|l|l|l|}
\hline Parameters & $\begin{array}{l}\text { Vertical } \\
\text { impulse } \\
\text { Vertical } \\
\text { reaction } \\
\text { (Figure 5) }\end{array}$ & $\begin{array}{l}\text { Horizontal } \\
\text { impulse } \\
\text { Vertical } \\
\text { reaction } \\
\text { (Figure 6) }\end{array}$ & $\begin{array}{l}\text { Vertical } \\
\text { impulse } \\
\text { Horizontal } \\
\text { reaction } \\
\text { (Figure 7) }\end{array}$ & \multicolumn{2}{l|l}{$\begin{array}{l}\text { Horizontal } \\
\text { impulse } \\
\text { Horizontal } \\
\text { reaction } \\
\text { (Figure 8) }\end{array}$} \\
\cline { 2 - 10 } & B.S. & B.T. & B.S. & B.T. & B.S. & B.T. & B.S. & B.T. \\
\hline$T_{1}(\mathrm{~ms})$ & 150 & 130 & 35 & 50 & 35 & 120 & 65 & 80 \\
\hline$T_{2}(\mathrm{~ms})$ & 25 & 50 & 18 & 20 & 25 & 50 & 18 & 20 \\
\hline$f_{1}(\mathrm{~Hz})$ & 7 & 8 & 29 & 20 & 20 & 8 & 15 & 20 \\
\hline$f_{2}(\mathrm{~Hz})$ & 40 & 20 & 56 & 50 & 40 & 20 & 56 & 50 \\
\hline$p_{1}(\mathrm{rad} / \mathrm{s})$ & 44 & 50 & 182 & 126 & 182 & 50 & 94 & 75 \\
\hline$p_{2}(\mathrm{rad} / \mathrm{s})$ & 251 & 126 & 352 & 314 & 251 & 126 & 352 & 314 \\
\hline$\overline{\mathrm{X}_{1}}$ & 1,6 & 1,3 & 1,2 & 0,9 & 1,1 & 1,1 & 1,1 & 1,1 \\
\hline$x_{\mathrm{i}}+1$ & 1,1 & 1,1 & 0,8 & 0,6 & 0,7 & 0,6 & 0,8 & 0,6 \\
\hline$\delta$ & 0,4 & 0,2 & 0,4 & 0,4 & 0,5 & 0,6 & 0,3 & 0,3 \\
\hline$\lambda^{*} 10^{-3}$ & 2,6 & 1,5 & 11,4 & 8 & 14,3 & 5 & 4,6 & 3,7 \\
\hline
\end{tabular}

The graphic value of vibration to headstock are in figures 5, 6, 7 and 8 . 


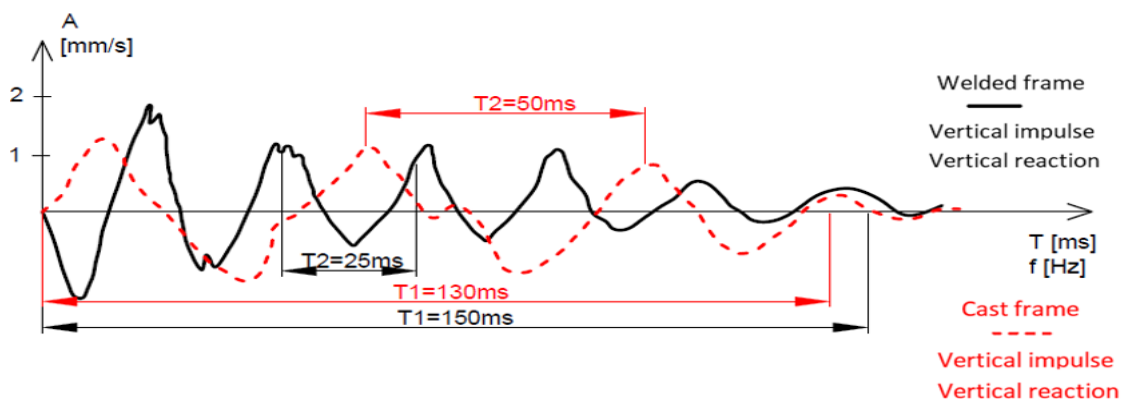

Fig. 5. Vertical impulse and vertical reaction.

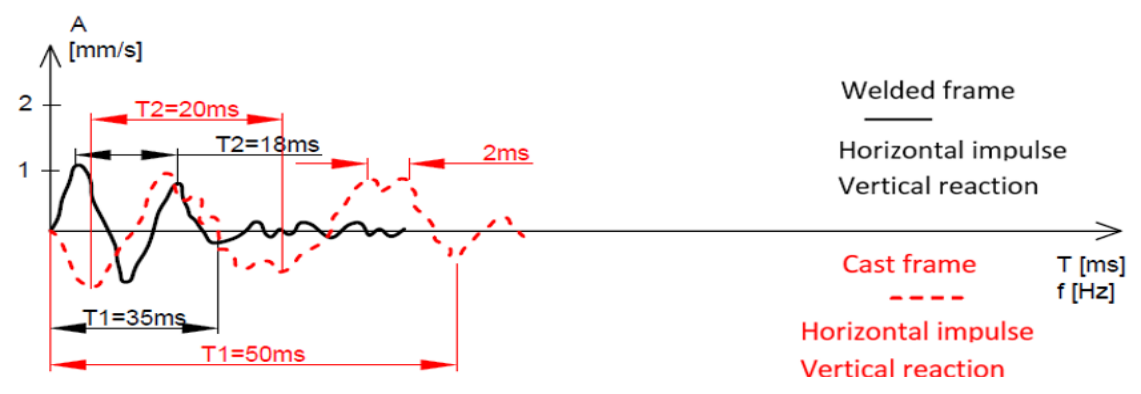

Fig. 6. Horizontal impulse and vertical reaction.

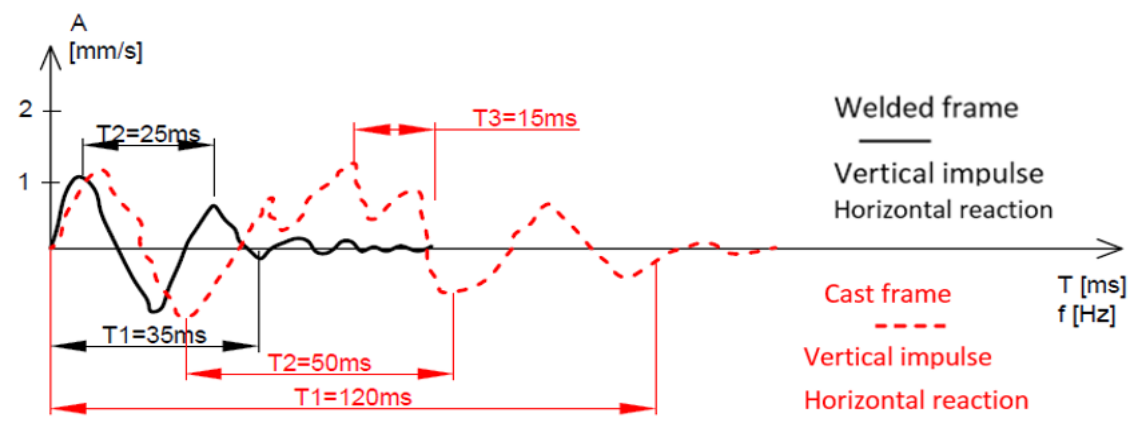

Fig. 7. Vertical impulse and horizontal reaction.

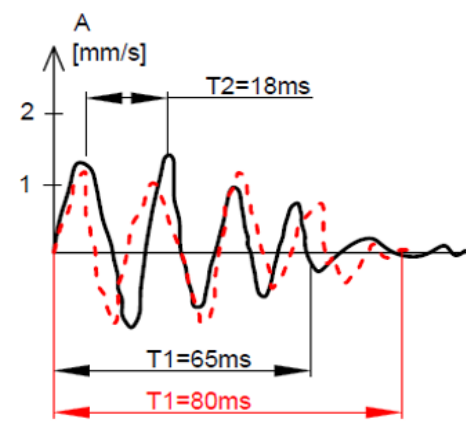

Welded frame

Horizontal imnulse Horizontal reaction
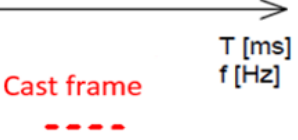

Horizontal impulse Horizontal reaction

Fig. 8. Horizontal impulse and horizontal reaction. 


\section{Results and conclusions}

Besides headstock arousal and response. Welded to the frame of the vertical frequency of the impulse response is $40 \mathrm{~Hz}$, the period of $150 \mathrm{~ms}$ damping being greater in vertical direction than in the horizontal direction $35 \mathrm{~ms}$. To the framework poured vertical impulse frequency response is $20 \mathrm{~Hz}$, the amortization period is approximately the same in horizontal and vertical direction. Comparing welded frameworks and poured observed that the cast machine frame has a damping factor better than $\lambda$ welded machine frame.

The frequency response of frameworks with excitement next of the tailstock have the same values as the next of the headstock excitement under the same excitement and response.

The momentum in the horizontal direction on the bedframe environment shows that it's response takes a place on other frequencies and payback lower than the vertical impulse.

From factors we can observed that the framework coefficient $\lambda$ is better than the molded that welded structures.

\section{References}

1. D. Glăvan, I. Radu, Vibrațiile mecanice în tehnică (Editura Universității „Aurel Vlaicu”, Arad, 2001)

2. D. Glăvan, I. Radu, Elemente vibrații mecanice (Editura Universității „Aurel Vlaicu”, Arad, 2001)

3. D. Glăvan, T. Babanatsas, Mașini unelte și aggregate (Editura Universității „Aurel Vlaicu”, Arad, 2002)

4. H. Meyer, F. Fuchs, and K. Thiel, Manufacturing Execution Systems: Optimal Design, Planning, and Deployment. (McGraw Hill, 2009)

5. L. Cîndea , C. Hatiegan, G.R. Gillich, C. Marta, M. Nedeloni, Scientific Bulletin of the "Politehnica" University of Timisoara, Transaction on Mathematics \& Fhysics, 57, 68 (2012)

6. Y. Rodichev, O. Soroka, V. Kovalov, Y. Vasilchenko, V. Maiboroda, Journal of Research and Development in Mechanical Industry, 7, 1 (2015)

7. V.D. Kovalev, Y.V. Vasilchenko, and P. Dašiü, Journal of Mechanics Engineering and Automation, 4, 269 (2014)

8. L. Hakansson, Adaptive Active Control of Machine-Tool Vibration in a Lathe - Analysis and experiments (Lund Univ., Sweden, 1999)

9. I. Claesson, L. Håkansson, Int. J. Acoust. Vib., 3, 4 (1998)

10. N. Deshpande, M.S. Fofana, Comput. Integr. Manuf., 17, 1 (2001)

11. W. de Silva Clarence, Vibration Signal Analysis, in: Mechanical Engineering Series, Frank Krith, Vibration and Shock Handbook (Taylor and Francis Group, LLC, 2005) 